
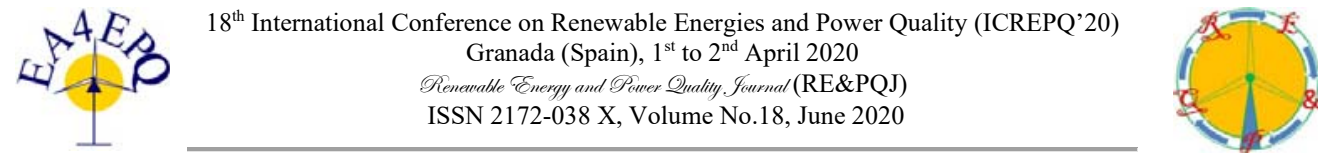

\title{
Analysis and Modeling of Environmentally Friendly Heat Pump Systems
}

\author{
M. Idrus Alhamid, Nyayu Aisyah, Arnas Lubis and Nasruddin \\ Department of Mechanical Engineering \\ Universitas Indonesia \\ Kampus Baru UI Depok, 16424 (Indonesia) \\ Phone/Fax number: +62 2172700 33/32, e-mail: mamak@eng.ui.ac.id
}

\begin{abstract}
A simulation approach to heat pump systems is proposed in this paper. The evaluation of working fluids is conducted. Some alternative refrigerants, including R245fa, R32, R1234ze, and R1224yd are investigated. Moreover, the selected refrigerants are used in the simulation. The simulation is conducted using MATLAB software. Subsequently, the system is analyzed in terms of the coefficient of performance (COP) and exergy efficiency. The results indicate that R1224yd is the best refrigerant with regards to safety, environmental impact, and physical properties. Based on the energy and exergy analysis, R1224yd can attain a COP of 6.5 and exergy efficiency of $29.8 \%$.
\end{abstract}

Keywords: Heat pump, working fluid, COP, exergy

\section{Introduction}

One of the problems in heating, ventilation, and air conditioning (HVAC) systems is finding an alternative refrigerant that can provide high system performance but have low environmental effects (Nasruddin et al., 2017). The world's attention to environmental damage is known to continually increase; hence, efforts in finding alternative refrigerants continue to be conducted. This began from the issue of the ozone layer damage (Fukuda et al., 2014) that was discussed in 1987, leading to a ban on the use of substances that can damage the ozone, namely chlorofluorocarbon (CFC) refrigerants, which led to the issuance of the Montreal Protocol. Subsequently, the effects of global warming in 1990 were the basis for the formulation of the Kyoto Protocol, which contained directions on the use of low global warming potential (GWP) refrigerants such as hydrofluoroolefin (HFO), hydrofluorocarbon (HFC), hydrochlorofluoroolefin (HCFO), and a mixture of HFC with HFO or even the consideration of refrigerants that have been used previously, such as water, ammonium, and hydrocarbons (Beshr et al., 2016; Steve and Ken, 2016).

The facts stated above indicate that energy and the environment are interrelated; therefore, considering environmental aspects in meeting energy requirements is necessary (Nasruddin et al., 2019). An environmentally friendly refrigeration system is one of the solutions offered by researchers as an efficient and high-performance system (Curtis et al. 2005; Omer 2008). This system is considered capable of reducing primary energy consumption and offering an efficient equipment (Chua et al. 2010; Jensen et al. 2015). Vapor compression refrigeration and absorption systems are two technologies that have been developed recently (Curtis et al., 2005).

From the development of research on refrigeration systems and heat pumps, one of the prominent efforts in improving system efficiency and reducing the impact of systems on the environment is the evaluation of various alternative refrigerants. Recently, various alternative refrigerants have emerged such as R1234ze, R452B, R447B, etc. Mastrullo et al. attempted to a simulation to determine the performance of refrigeration systems using R1234ze and R1234yf. The results demonstrated that systems had a fairly good performance with a coefficient of performance (COP) ranging from 3.4 to 4.6 (Mastrullo et al., 2016). Other researchers, Ju et al. and Zhang et al., attempted reusing refrigerants from the hydrocarbon group to overcome the environmental problems caused by current systems with synthetic refrigerants. Ju used R744 and R290 for refrigeration systems, and the results indicated that systems had very good performance with a COP ranging from 4.5-4.7 (Ju et al., 2018). Similarly, the simulation conducted by Zhang et al., where a refrigeration system using the working fluid R744 had good performance with a COP ranging from 3.25- 4.25 (Zhang et al., 2017).

\section{Methodology}

In this study, an evaluation of some alternative refrigerants was conducted to compare some alternative refrigerants in terms of safety, environmental impact, and performance. The model of the system in this study used Matlab 2017a software and REFPROP ver 10. The selection of working fluids that could be used in this study illustrated in Figure 1.

High critical temperatures provided a significant possibility to transfer heat at high temperatures with a critical cycle. Moreover, the critical pressure had to be low. In addition, zero ozone depletion potential (ODP) and zero GWP were required to be considered. Based on Ashrae's classification, the working fluid used was to be 
in the A1 category, which means non-toxic and nonflammable (Ashrae, 2010). Table 1 provides information

on the properties of environmentally friendly refrigerants.

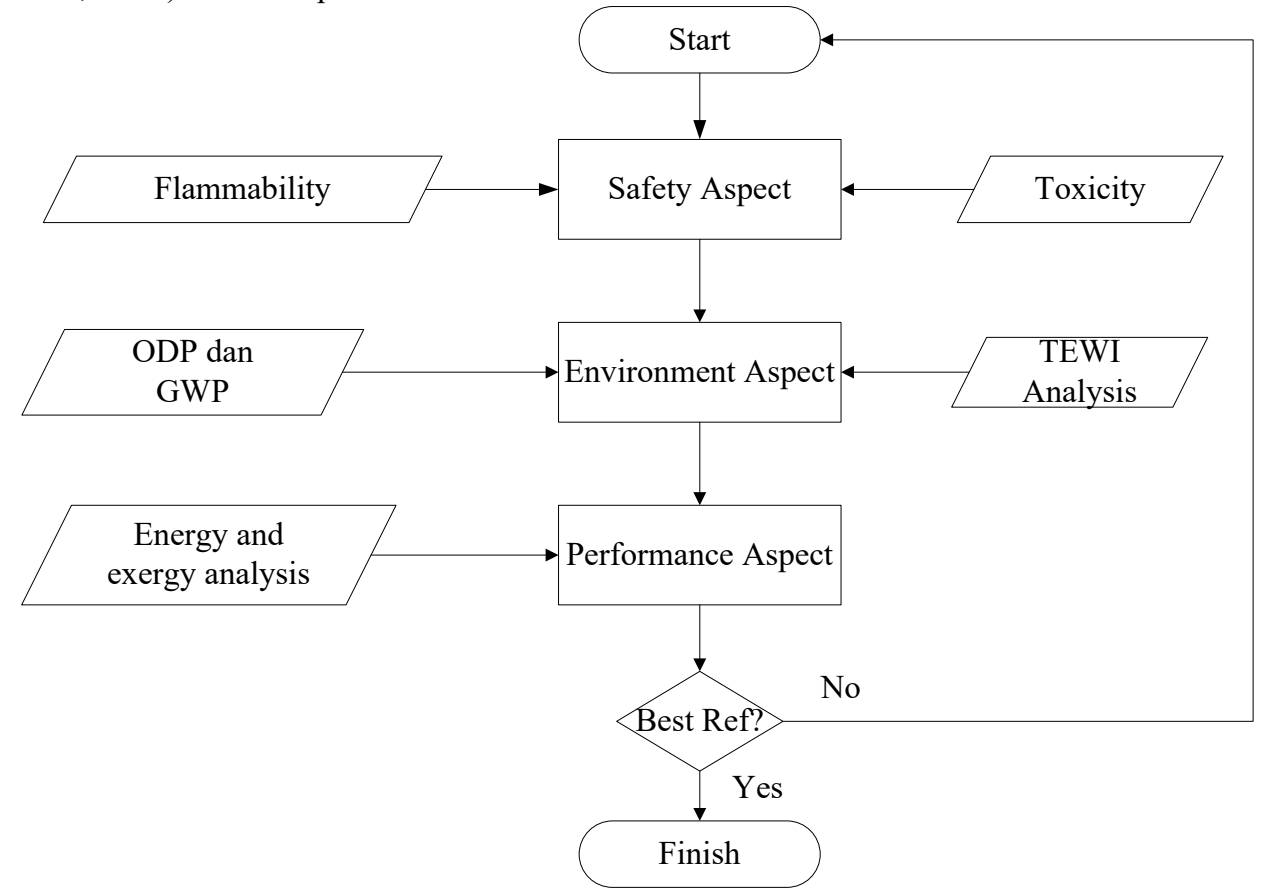

Figure 1. Refrigerant evaluation

Table 1. Characteristics of some working fluids

\begin{tabular}{lllll}
\hline Parameter & R245fa & R32 & R1234ze & R1224yd \\
\hline Critical Temp $\left({ }^{\circ} \mathrm{C}\right)$ & 154 & 79 & 109.4 & 156 \\
Critical Pressure $(\mathrm{MPa})$ & 3.65 & 4.79 & 3.64 & 3.33 \\
GWP & 1030 & 550 & 6 & $<1$ \\
Safety Group & B1 & A2 & A2L & A1 \\
\hline
\end{tabular}

The analysis of the environmental aspects of the heat pump system in this study was as follows (Mastrullo, 2016):
TEWI $=$ direct emissions + indirect emissions
$=(\mathrm{GWP} \times \mathrm{L} \times \mathrm{N})+(\mathrm{Ea} \beta \mathrm{n})$

$$
\begin{array}{ll}
\text { where } & \\
\text { TEWI } & =\text { Total Equivalent Warming Impact } \\
\mathrm{L} & =\text { refrigerant leakage in Kg (Estimation } \\
\mathrm{N} \text { of charge) } & \\
\mathrm{N} & =\text { system life span (years) } \\
\mathrm{Ea} & =\text { Energy consumption }(\mathrm{KWh} / \text { year) } \\
\beta & =\mathrm{CO}_{2} \text { emission factor }(0.483 \mathrm{~kg} \\
\left.\mathrm{CO}_{2} / \mathrm{kWh}\right) & \\
\mathrm{n} & =\text { system running time in one year }
\end{array}
$$
$3 \%$ of charge)

$\mathrm{CO}_{2} / \mathrm{kWh}$

Thermodynamic calculations on the heat pump system were conducted by simulating each thermodynamic state. All thermophysical properties and theoretical characteristics of refrigerants were obtained from the database owned by REFPROP software. The calculation process was conducted using the MATLAB $2017 \mathrm{~b}$ version program.
MATLAB is a computer program that facilitates solving various mathematical problems that are often encountered in technical fields. MATLAB can find solutions to numerical problems quickly, ranging from simple equations to complex ones, such as the interpolation of a number of data, searching for polynomial roots, matrix calculations, signal processing, numerical methods, and optimization (Teguh, 2005).

REFPROP was developed by the National Institute of Standards and Technology (NIST) to calculate the thermodynamic and transport properties of industrial fluids and their mixtures. This property can be displayed in tables and plots through the use of graphics and can also be accessed through spreadsheets or applications that can access REFPROP such as MATLAB. REFPROP is based on the most accurate pure fluid and mixture models available today. This software implements three models for pure fluid thermodynamic properties, namely, equations of state explicit in the Helmholtz energy, modified Benedict-Webb-Rubin equations, and extended corresponding state (ECS) models. Mixed calculations use a model that applies the mixing rule with Helmholtz energy from mixed components. Viscosity and thermal conductivity are modeled using fluid-specific 
correlations, the ECS method, or, in some cases, the friction theory method.

The thermodynamic analysis of the system is carried out with the following assumptions:

- The system is in a steady state.

- Pressure drop is ignored on the piping system.

- The expansion of the refrigerant is assumed to be isenthalpic.

Based on the above assumptions, an analysis of thermodynamics was conducted. The COP was calculated using the following equation:

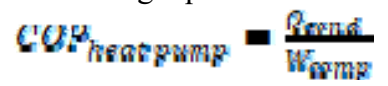

where

$\mathrm{COP}_{\text {heat pump }}$

$\mathrm{Q}_{\text {cond }}$

$(\mathrm{kW})$

$\mathrm{W}_{\text {comp }}$

$=$ coefficient of performance

$=$ energy in the condenser side

$=$ compressor work $(\mathrm{kW})$

Subsequently, the exergy calculation can be obtained from Table 2.

Table 2 Calculation of exergy destruction of each system component

\begin{tabular}{ll}
\hline Component & Exergy destruction Equation \\
\hline Evaporator & Exe $_{\mathrm{e}}=\mathrm{m}_{\mathrm{ref}}\left(\mathrm{Ex}_{4}-\mathrm{Ex}_{1}\right)+\left[1-\left(\mathrm{T}_{\mathrm{a}}-\mathrm{T}_{\mathrm{cl}}\right)\right] \mathrm{Q}_{\mathrm{e}}$ \\
Compressor & $\mathrm{Ex}_{\mathrm{co}}=\mathrm{W}_{\mathrm{co}}-\mathrm{m}_{\mathrm{ref}}\left(\mathrm{Ex}_{2}-\mathrm{Ex}_{1}\right)$ \\
Condenser & $\mathrm{Ex}_{\mathrm{c}}=\mathrm{m}_{\mathrm{ref}}\left(\mathrm{Ex}_{2}-\mathrm{Ex}_{3}\right)-\left[1-\left(\mathrm{T}_{\mathrm{a}}-\mathrm{T}_{\mathrm{c}}\right)\right] \mathrm{Q}_{\mathrm{c}}$ \\
Ex valve & $\mathrm{Ex}_{\mathrm{v}}=\mathrm{m}_{\mathrm{ref}} \mathrm{LT}\left(\mathrm{Ex}_{5}-\mathrm{Ex}_{6}\right)$ \\
\hline
\end{tabular}

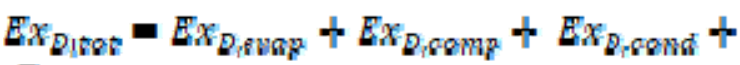

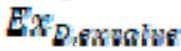

(2)

$$
\begin{aligned}
& E x_{i n}=W_{s e} \\
& E x_{n f f}=1-\frac{E x_{p w n}}{E x_{i n}}
\end{aligned}
$$

\section{Result and Discussion \\ A. Evaluation of Refrigerant Selection}

The evaluation of refrigerants plays an important role in the heat transfer process that occurs in a system. This was the initial stage carried out in this study. As explained in the previous section, various aspects are considered in the selection of refrigerants, beginning with physical properties, safety, and the impact of the system on the environment. Figures 2 and 3 are the results of evaluations conducted by considering various alternative refrigerants.

Furthermore, Figure 3 presents the results of evaluating various refrigerants with regard to physical properties that include low pressure and high critical temperature. Moreover, environmental aspects such as ODP values at approximately 0 and GWP that are approximately 1 were the best selection criteria for refrigerants. Finally, the other criteria were the safety aspect and the refrigerant being classified as toxic and flammable. By collecting the data in Table 1, and further information, the normalized values as seen in Table 3 are presented in the spider plot diagram in Figure 3.

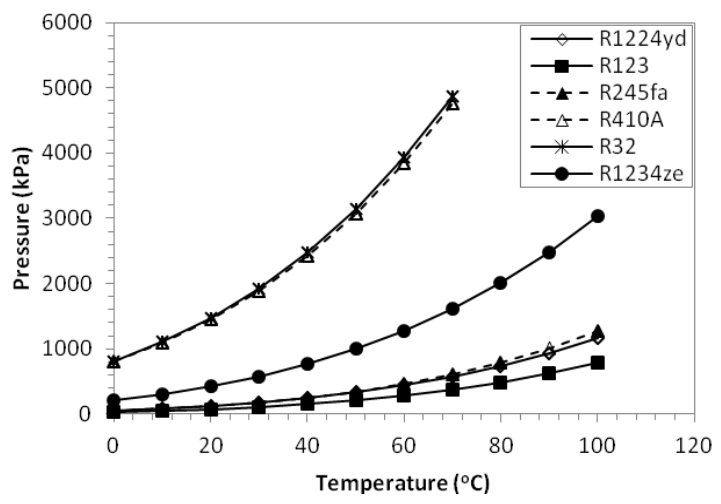

Figure 2 P-T Diagram of some alternative refrigerants

Figure 2 shows the pressure and temperature properties of some refrigerants. The figure shows that, at the same temperature, R410a and R32 have a higher pressure than other refrigerants. R1224yd tends to have the same trend as R245fa and R123. Subsequently, Figure 3 shows a comparison of various refrigerants with five parameters, namely, pressure, temperature, GWP value, ODP value, and safety class. The figure shows that R1224yd has a very good value indicated by the coverage of the area formed in the form of a perfect rectangle. This indicates that R1224yd is the best among the refrigerants in terms of physical properties, safety aspect, and ODP and GWP values.

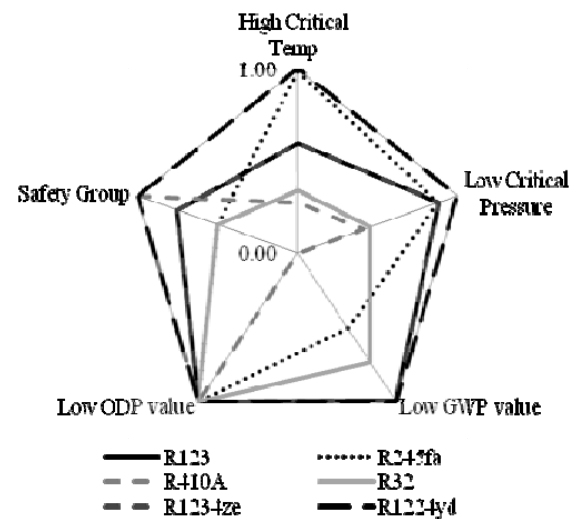

Figure 3. Spider plot comparison of some refrigerants

Furthermore, TEWI's analysis was carried out to observe the impact refrigerants used in heat pump systems have on the environment. From the results of the calculations, as shown in Figure 4, R1224yd has the lowest TEWI value or environmental impact compared with R1234ze, R32, R245fa, R123, and R410A. R1224yd emits approximately $760 \mathrm{~kg}$ of $\mathrm{CO}_{2}$ per year for indirect impact and $4 \mathrm{~kg}$ of $\mathrm{CO}_{2}$ per year for direct impact. Thus, 
R1224yd can be an alternative refrigerant or regarded as the system designed in this study. an environmentally friendly alternative working fluid in

Table 3. Information on the selection criteria for the best refrigerants

\begin{tabular}{lcccccc}
\hline Parameter & R123 & R245fa & R410A & R32 & R1234ze & R1224yd \\
\hline Critical Temp & 0.60 & 0.98 & 0.27 & 0.34 & 0.60 & 1.00 \\
Critical Pressure & 0.88 & 0.88 & 0.41 & 0.45 & 0.88 & 1.00 \\
GWP & 1.00 & 0.51 & 0.01 & 0.74 & 1.00 & 1.00 \\
Safety Group & 1.00 & 1.00 & 1.00 & 1.00 & 1.00 & 1.00 \\
ODP value & 1.00 & 1.00 & 1.00 & 1.00 & 1.00 & 1.00 \\
\hline
\end{tabular}

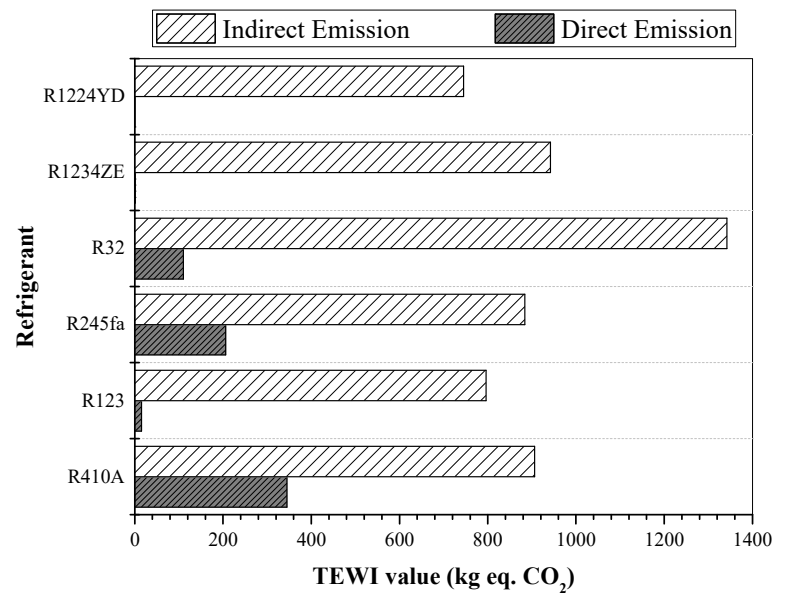

Figure 4. TEWI Analysis of Various Refrigerant Alternatives

\section{B. Modeling heat pump system \\ The Effect of Evaporation Temperature on System Performance}

A parametric study was conducted to observe the effect of evaporation temperature, condensation temperature, and mass flow rate of refrigerants on system performance, which includes compressor work, heating load, and system COP value. The evaluated system was a single-stage vapor compression system for air conditioning using R1224yd as the refrigerant. Figures 5, 6, and 7 show the effects of evaporation temperature variations on various system performance parameters. Figure 5 shows that, when the evaporation temperature varied from 8 to 16 ${ }^{\circ} \mathrm{C}$, the compressor's work decreased from 920 to $630 \mathrm{~W}$. The work of the compressor would then affect the value of the system COP and exergy efficiency. The trend of the system COP value can be seen in Figure 6 while the value of exergy efficiency is shown in Figure 7.

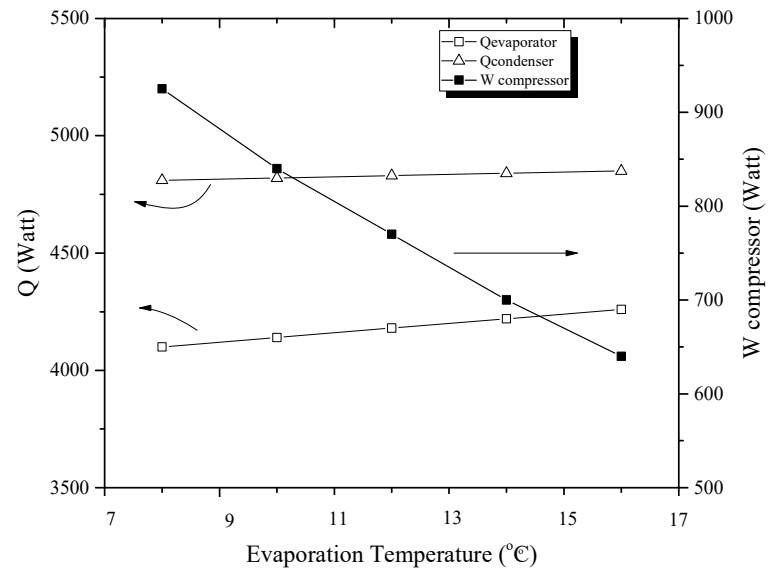

Figure 5 Effects of evaporation temperature on Q and compressor work

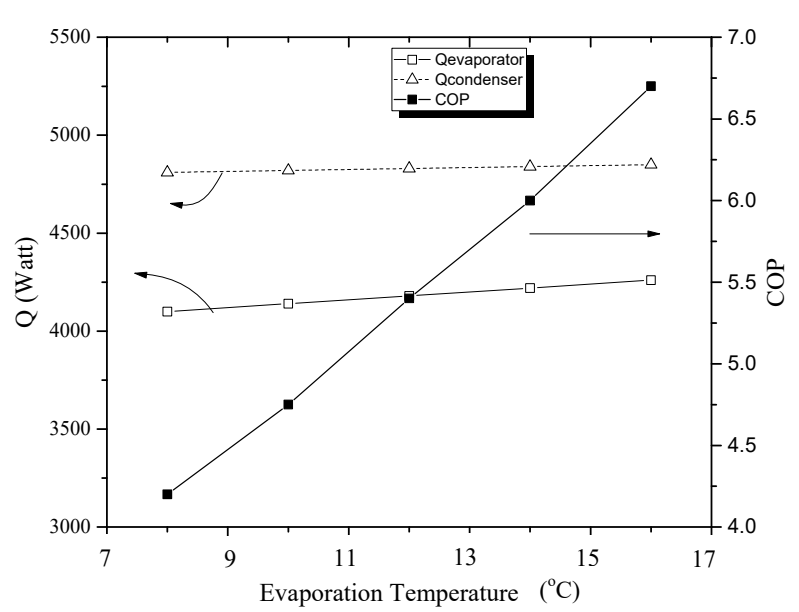

Figure 6. Effects of evaporation temperature on $\mathrm{Q}$ and COP 


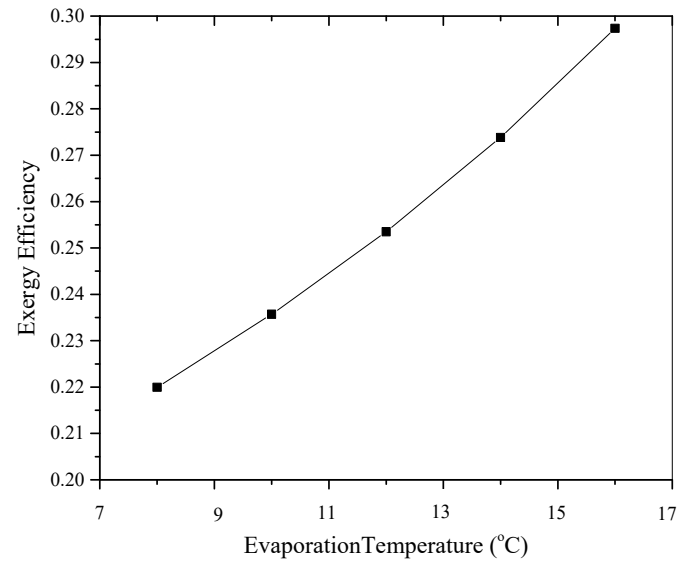

Figure 7. Effects of evaporation temperature on exergy efficiency

The Effect of Condensation Temperature on System Performance

Figures 8, 9, and 10 show the effects of condensation temperature variations on various system performance parameters. Figure 8 shows that, when the condensation temperature varied from 40 to $48{ }^{\circ} \mathrm{C}$, the compressor's work increased from 850 to $1100 \mathrm{~W}$. The work of the compressor then affected the value of the system COP and exergy efficiency. The trend of the system COP value is shown in Figure 9 while the value of exergy efficiency is shown in Figure 10.

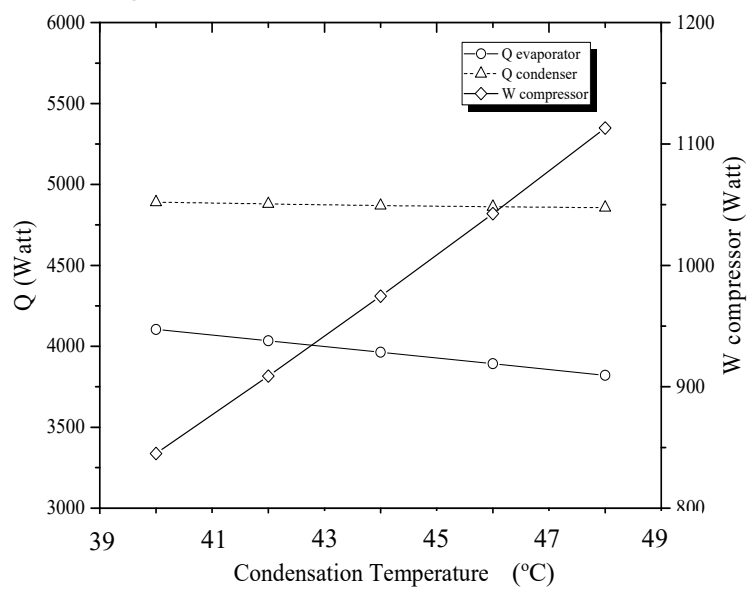

Figure 8 Effects of Temperature Condensation on Q and

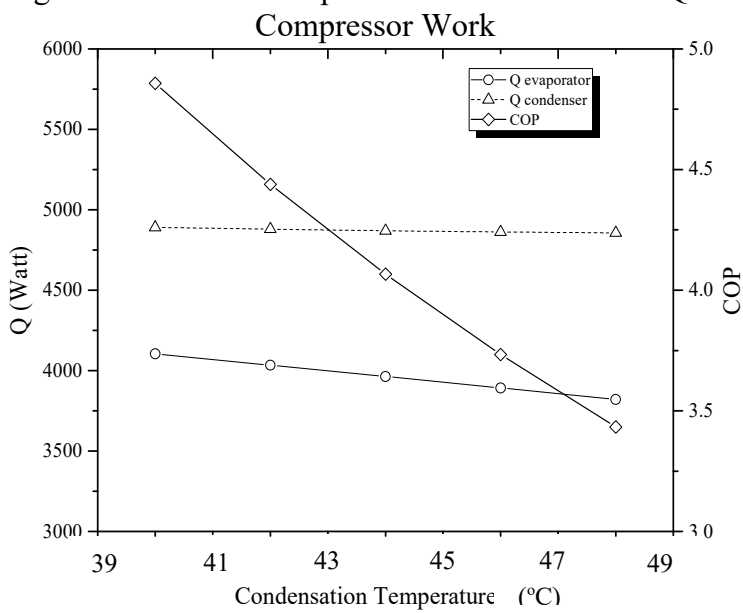

Figure 9 Effects of Temperature Condensation on Q and COP
Figure 9 indicates that when the condensation temperature varied from 40 to $48{ }^{\circ} \mathrm{C}$, the value of the system COP decreased from 4.8 to 3.4 . This was due to the increasing condensation temperature; the compressor's work increased so that the system COP value decreased.

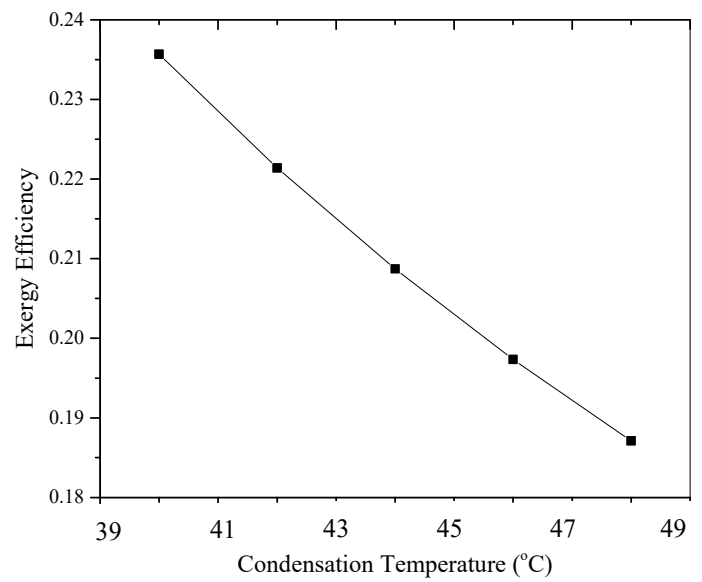

Figure 10. Effects of temperature condensation on exergy efficiency

The influence of condensation temperature on exergy efficiency was as shown in Figure 10. Exergy efficiency decreased from 23 to $19 \%$ when the condensation temperature varied from 40 to $48^{\circ} \mathrm{C}$. This was because as the condensation temperature increased, a large difference occurred between the temperature of the working fluid and that of the environment; hence, the exergy destruction rate increased and the efficiency of the exergy decreased.

\section{Conclusion}

Based on the refrigerant evaluation, R1224yd is the best refrigerant from aspects of safety, environmental impact, and physical properties when compared to various other alternative refrigerants such as R1234ze, R32, R123, and R245fa. R1224yd has the lowest indirect impact on the environment at $780 \mathrm{~kg}$ of $\mathrm{CO}_{2}$ and a direct impact that is about $0.2 \mathrm{~kg}$ of $\mathrm{CO}_{2}$. R1224yd was selected as the refrigerant for a heat pump system. According to the result of the system modeling, the system using R1224yd has COP ranging from 4.6 to 6.5 and exergy efficiency ranging from $22 \%$ to $29.8 \%$ at an evaporation temperature of $8-16{ }^{\circ} \mathrm{C}$.

\section{Acknowledgment}

This work is supported by the Ministry of Higher Education of Indonesia with Research Grant PDUPT 2019.

\section{References}

[1] Beshr, M., et al. (2016). "Multi-objective optimization of a residential air source heat pump with small-diameter tubes using genetic algorithms." International Journal of Refrigeration 67: 134-142. 
[2] Curtis, R., et al. (2005). Ground source heat pumpsgeothermal energy for anyone, anywhere: current worldwide activity. Proceedings World Geothermal Congress, Antalya, Turkey.

[3] Chua, K. J., et al. (2010). "Advances in heat pump systems: A review." Applied energy 87(12): 3611-3624.

[4] Fukuda, S., Kondou, C., Takata, N., \& Koyama, S. 2014. Low GWP refrigerants R1234ze (E) and R1234ze (Z) for High Temperature Heat Pumps. International Journal of Refrigeration, Volume 40. pp. $161-173$.

[5] Jensen, J. K., et al. (2015). "Exergoeconomic optimization of an ammonia-water hybrid absorption-compression heat pump for heat supply in a spray-drying facility." International Journal of Energy and Environmental Engineering 6(2): 195211.

[6] Ju, F., et al. (2018). "Experiment and simulation study on performances of heat pump water heater using blend of R744/R290." Energy and Buildings 169: 148-156.

[7] Mastrullo, R., et al. (2016). "Refrigerant alternatives for high speed train A/C systems: energy savings and environmental emissions evaluation under variable ambient conditions." Energy Procedia 101: 280-287.

[8] Nasruddin, M., Aisyah, N., Alhamid, M.I., Saha, B.B., Sholahuddin, S., Lubis, A., 2019. Solar Absorption Chiller Performance Prediction Based on the Selection of Principal Component Analysis. Case Studies in Thermal Engineering, Volume 13, p. 100391.

[9] Nasruddin, M., Alhamid, I., Aisyah, N., 2017. Energetic, Economic and Environmental (3E) Optimization of Solar Assisted Heat Pump Using Low GWP Refrigerant R1234ze(E) for High Temperature Application. Published in: 2017 3rd International Conference on Power Generation Systems and Renewable Energy Technologies (PGSRET), pp. 79-84.

[10] Omer, A. M. (2008). "Energy, environment and sustainable development." Renewable and Sustainable Energy Reviews 12(9): 2265-2300.

[11] Steve and Ken. (2016). "Insight into the next generation HVAC\&R refrigeration system". Science and Technology for Built Environment, 22, pp. 1226 - 1237.

[12] Zhang, X., et al. (2017). "Performance Research on Heat Pump Using Blends of R744 with Eco-friendly Working Fluid." Procedia Engineering 205: 2297-2302. 